added the mere athlete. In reviewing the various form of athletics which are practised in schools, he throws out many hints valuable to all concerned in the care of young people. We would like to see the pamphlet widely read, and its principles as generally put into practice.

Military Drill as a Means of Physical Training for Boys. By Charles F. Withington, M.D. Boston Medical and Surgical Journal, May 13, 1886.

AN interesting comparison of the place occupied by athletic exercises in the public schools of Great Britain, and of Boston and other parts of America, may be made by carefully reading this paper and contrasting it with the one referred to above. We thus learn that military drill, and not a great amount of that, is the only recognised form of physical exercise in the larger schools of Boston and many other towns of the United States. Dr Withington's object in writing this paper is to oppose the confidence usually placed in military drill as a means of exercise, and to advoca other forms better calculated to attain the desired end. He shows that the war fever in 1863 is responsible for the presence of military drill in schools, and draws attention to the omission in more recent years of drill in the open air and of military gymnastics, which were part of the original plan.

He sums up his objections "to military drill as a sole means of physical culture for growing boys" as follows:-

1. The anatomical objection, based upon the fact of the obliquity of the superincumbent weight with reference to the spinal axis.

2. The physiological objection, based on the production of a tension of the muscles, rather than of that constant alternation of activity and repose which best conduces to their nutrition.

3 . What may be called the philosophical objection, based on a lack of adaptation in design for the end to which the system has been converted.

The subject is calmly and fairly discussed, and an unbiassed reader cannot fail to see that $\mathrm{Dr}$ Withington is in the right.

\title{
Year-Book of the Scientific and Learned Societies of Great Britain
} and Ireland. Third Annual Issue. London: Griffin \& Co.: 1886.

WE have already pointed out the great value of this book in noticing the two former issues. The present contains, in addition to the lists of papers read before the Societies in 1885, a note of the publications of the Scientific Departments connected with the State. 